\title{
Intra- and interlaboratory variability of allergen-specific IgE levels in atopic dogs in three different laboratories using the $\mathrm{Fc}-\varepsilon$ receptor testing
}

\section{Introduction}

Atopic dermatitis (AD) is one of the most common canine skin diseases, affecting $3-15 \%$ of the population (Scott and Paradis, 1990; Scott et al., 2001; Hillier and Griffin, 2001; Reedy et al., 2002). It is defined as a genetically predisposed inflammatory and pruritic allergic skin disease with characteristic clinical features associated with IgE antibodies most commonly directed against environmental allergens (Halliwell, 2006). Canine AD is diagnosed by clinical criteria according to Willemse (1986) and Prelaud (1998), after exclusion of differential diagnoses of pruritus. Allergen-specific IgE concentrations are only one of many criteria for $\mathrm{AD}$. Testing for allergen-specific IgE to identify environmental antigens which elicit an allergic response in the individual dog however is a precondition for allergen-specific immunotherapy (ASIT). ASIT is a commonly used and well-accepted therapy for humans and dogs with atopic diseases (James and Durham, 2008; Griffin and Hillier, 2001; Reedy et al., 2002; Keppel et al., 2008). Several types of serologic tests have been developed and are widely used in veterinary practice, as they are easier to perform and not as time-consuming as intradermal allergy testing (IDT). These tests are based on the measurement of allergenspecific IgE concentrations by ELISA using mono- or polyclonal antibodies or the $\mathrm{Fc}-\varepsilon$ receptor technique. The method evaluated in this study is the $\mathrm{Fc}-\varepsilon$ receptor test developed by Heska Corporation (Fort Collins, USA) and now available in various laboratories in Europe. These laboratories are “Allercept ${ }^{\circledR}$ Program Lab Partners”, provided with defined test reagents and trained in the test procedure. Each laboratory can choose its specific panel of allergens. The test uses a recombinant a-chain of the human high affinity IgE receptor (FceR1a) which has been shown to be highly specific for canine IgE antibodies (Wassom and Grieve, 1998; Stedman et al., 2001). In human medicine accredited laboratories perform tests to verify reproducibility and accuracy of measurements in different laboratories using identical methods. In veterinary medicine quality assurance programmes are implemented at the discretion of the laboratories. To the authors' knowledge there are no studies that have investigated intra- and interlaboratory variability of the $\mathrm{Fc}-\varepsilon$ receptor test in different veterinary laboratories. The purpose of this study was to evaluate intralaboratory and interlaboratory variability of the $\mathrm{Fc}-\varepsilon$ receptor test in three laboratories. 


\section{Material and methods}

\subsection{Study population}

Fifteen atopic dogs of 14 different breeds with an age ranging from 1 to 11 years (mean age 4.3 years) from 3 different dermatological services (Tiera“ rztliche Spezialisten Hamburg, Dermatological Unit of Vetsuisse Faculty of Zurich, Dermatological service of Justus-LiebigUniversity of Giessen) were included in the study. Diagnosis of ADwas based on compatible history and clinical criteria (Willemse, 1986; Prelaud, 1998). Other pruritic diseases, such as parasitic, bacterial or fungal diseases were excluded by appropriate diagnostic tests. Food adverse reaction was ruled out by failure to respond to an appropriate 8-week elimination diet. All dogs except one underwent IDT with 44-45 common allergens (Greer Laboratory, Lenoir, North Carolina) as a routine diagnostic procedure. Dogs were sedated with either medetomidine or xylazine, injection of allergens (Greer Laboratory, Lenoir, North Carolina) and interpretation of reactions were performed as described elsewhere (Reedy et al., 2002; Scott et al., 2001). Each dog was positive for at least one allergen. At the time of IDT, oral and topical glucocorticoids had to be withdrawn for 4 weeks, injectable glucocorticoids for 8 weeks, antihistamines for 2 weeks and cyclosporin for at least 4 weeks.

\subsection{Serum samples}

At the same time as IDT was perfomed, blood was drawn by puncture of the cephalic or jugular vein and centrifuged immediately after collection. The serum from each dog was divided in six equal aliquots which were stored at _ $188 \mathrm{C}$ until being sent to the participating laboratories in the subsequent 4 weeks. Samples were sent from Monday to Wednesday, to avoid shipping over the weekend.

\subsection{Laboratories}

Three laboratories (LA, LB, LC) participated in the study, all using Allercept1, developed by Heska Corporation, USA. One laboratory (Heska Ag, Fribourg, Switzerland), was aware of the study protocol, the other laboratories were not. However, all analyses were blinded as 
each specimen was labeled with a different dog and owner identity and batches from two to five dogs were sent in concurrently.

\subsection{Fc-e receptor test}

Serum concentrations of allergen-specific IgE antibodies were measured using the Fc-e receptor testing method as described elsewhere (Wassom and Grieve, 1998; Foster et al., 2003). LA and LC measured allergen-specific IgE for 36 allergens and expressed the results as optic density (OD) units, with a range from 0 to $>3000$ OD. Values of 150 OD and above were considered positive. In LB 16 allergens were analysed. Results of LB were provided in reaction grades $(\mathrm{RG})$ ranging from zero to five, depending on OD units in ELISA measurements (Table 1). Grade zero, identified as an optical density of less than 150 , was regarded as a negative test result, grade $1-5$ were interpreted as positive.

\begin{tabular}{|l|c|}
\hline Reaction Grade & Optic Density Units \\
\hline 0 & $\leq 150$ \\
\hline 1 & $151-250$ \\
\hline 2 & $251-500$ \\
\hline 3 & $501-1500$ \\
\hline 4 & $1501-3000$ \\
\hline 5 & $>3000$ \\
\hline
\end{tabular}

Table 1: Classification of Optic Density Units in Reaction Grades

\subsection{Statistical analysis}

For statistical analysis BMDP Statistical software 8.1 was used. For comparison between all three laboratories, OD units of LA and LC were translated into RG. Skewed data were 
transformed logarithmically to achieve a log-normal distribution. Intra- and interlaboratory variabilities were calculated by three factorial analysis of variance (mixed model). $\mathrm{p}<0.05$ was considered significant. For interlaboratory correlation, Pearson's (for parametric data of OD) or Spearman's correlation (for non parametric data of RG) were used. A correlation coefficient $r>0.8$ with a $p$ value of $<0.001$ was considered indicative of a good correlation.

\subsection{Intralaboratory analysis}

Duplicate measurements were used to assess intralaboratory variability. For OD results of LA and LC geometric mean, geometric standard deviation and the individual dispersion factor for each allergen were calculated. The dispersion factor is calculated for logarithmic data analogous to the standard deviation in non-logarithmic data for assessment of variance. The higher the dispersion factor, the greater is the variance. The lowest possible value of the dispersion factor is 1 , which means that there is no variance at all. The dispersion factor for the intralaboratory variability of the complete test was compared between LA and LC. The probability distribution function of the test was calculated. For LB only a descriptive analysis was possible due to abstracted results plotted in RG. Differences can only become obvious if data vary across class limits (see Table 1). Standard deviation (SD) and arithmetic mean were evaluated. Although possible, calculation of the coefficient of variance does not add more information on the intralaboratory variability, and was therefore not performed. Using the suggested cut-off point of $150 \mathrm{OD}$, results were classified as positive or negative. To assess intralaboratory differences regarding positive or negative results of the test, the percentage of differing measurements was calculated for each laboratory.

\subsection{Interlaboratory analysis}

Variability and correlation of OD results of each allergen was analysed comparing the duplicate measurements by three factorial analysis of variance (mixed model). Interlaboratory variability was assessed for RG of each allergen by evaluation of arithmetic mean and standard deviation. For interlaboratory correlation, Pearson rank correlation was used to compare LA/LB, LA/LC and LB/LC. To assess interlaboratory differences regarding positive or negative results of the test, the percentage of differing measurements was calculated. 


\section{Results}

Since data of OD units of LA and LC were positively skewed, they were transformed logarithmically. RG data were uniformly distributed, a logarithmic transformation was not necessary. LA and LC analysed allergen-specific IgE levels for 36 allergens in OD units and LB analysed 16 allergens in RG. Allergens which were measured only in one laboratory were excluded (Cryptomeria, rye, cedar). Altogether for LA and LC 35 allergens with 525 double measurements and for LB 15 allergens with 225 double measurements were included.

\subsection{Intralaboratory variability}

In Fig. 1 intralaboratory variability of LA and LC are depicted around 150 OD. The variation was calculated by the individual dispersion factor for each allergen. The cut-off point of 150 OD was chosen to demonstrate the variability around this value, as in low absolute OD values, small changes account for a relatively great variability. In the two laboratories the dispersion factor of individual allergens and their range did not differ significantly. Those measured by LA ranged from 1.15 (Birch) to 6.63 (English plantain). Corresponding values in LC ranged from 1.19 (Dermatophagoides (D.)farinae) to 6.17 (Salsola kali).

\section{OD units}

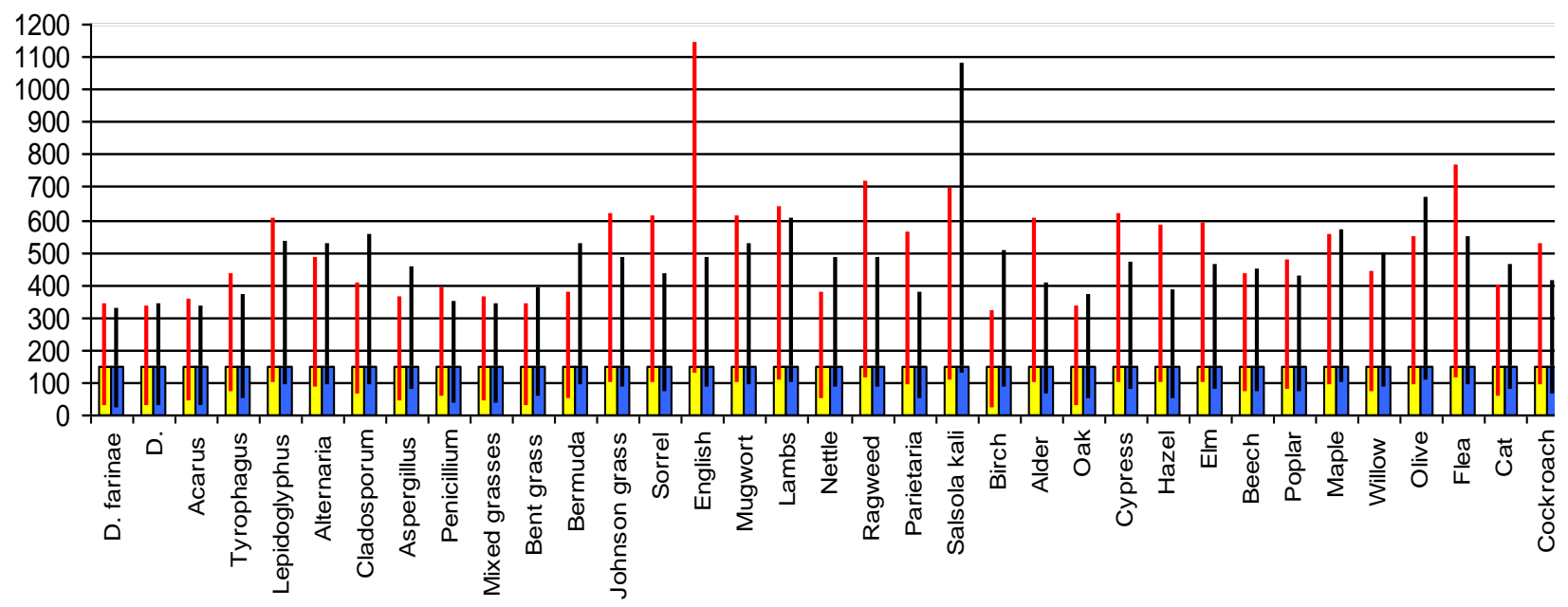

Figure 1:

Intralaboratory variability of $L A / L C$

Dispersion factor $(L A=$ red lines, $L C=$ black lines $)$ shown for the cut off value of 150 OD ( $L A=$ yellow, $L C=$ blue bars $)$ 
For assessment of the overall intralaboratory variability the dispersion factor of the complete test was evaluated. The dispersion factor for LA was 2.45 and for LC 2.19. Fig. 2 shows the probability distribution function. The function describes the range of possible values that a random variable can attain. It reflects the calculated probability to detect real positives by the test, depending on the measured value and the dispersion factor. The greatest variation in duplicate measurements was obtained in the range of OD values from 50 to 500. At an OD value of about 50, the probability to measure a false positive result was $10 \%$ and vice versa at an OD value of 500 the probability to get a false negative result was about $10 \%$.

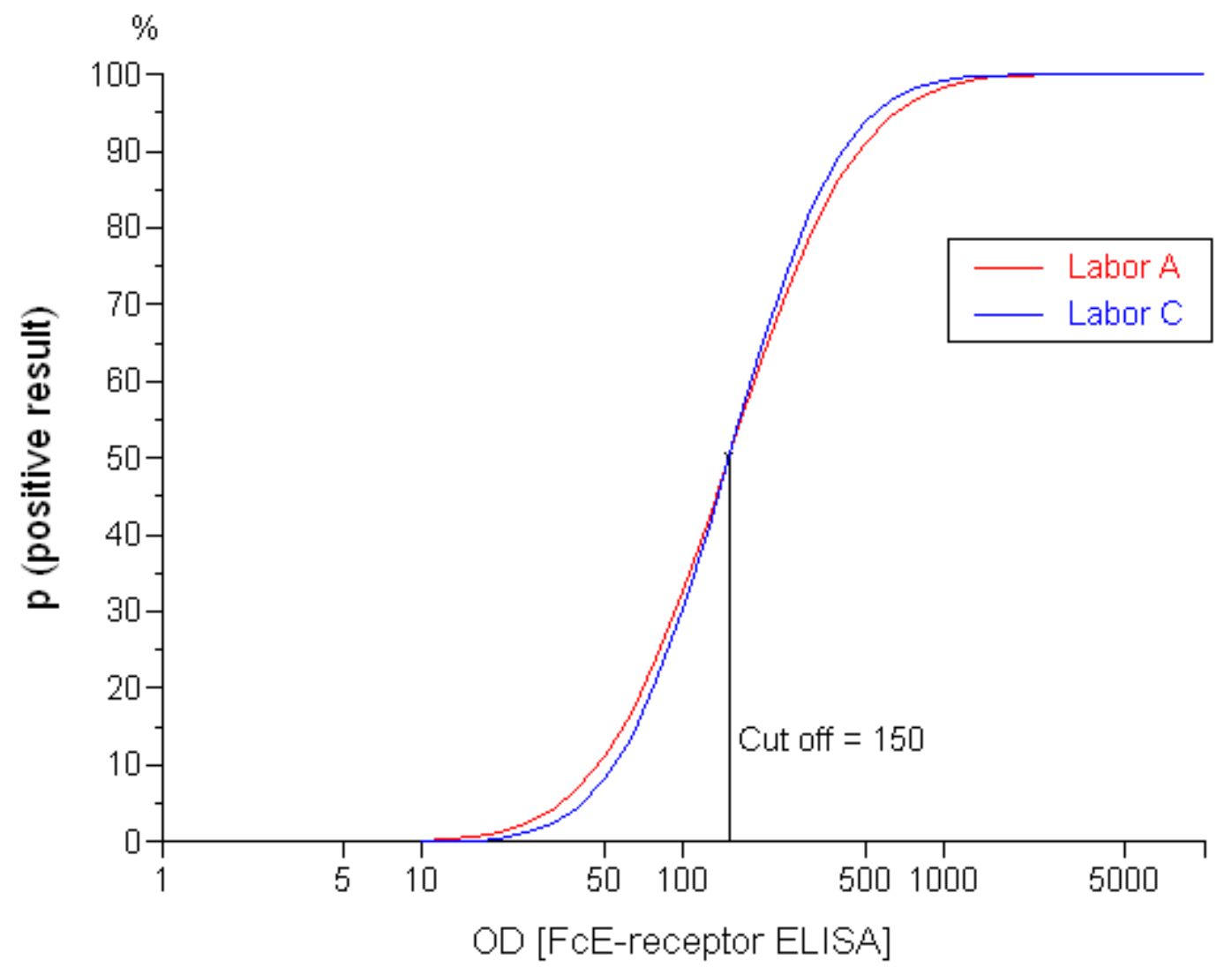

Figure 2 Probability distribution function

Probability for detection of real positives depending on measured value (calculation with log $O D$ in normal distribution) regarding overall intralaboratory dispersion factor 
Fig. 3 shows the intralaboratory variability of LB around the cut-off value of RG1, depicted as SD. SD ranges from $0 \mathrm{RG}$ for eight allergens to $0.61 \mathrm{RG}$ for $\mathrm{D}$. farinae. In LA as well as in LC 17 of 525 measurements (3.24\%) differed regarding positive or negative interpretation of allergy test results. LB reported differing results in 6 of 225 cases (2.66\%). Overall disparity was $3.14 \%$ (40/1275 measurements).

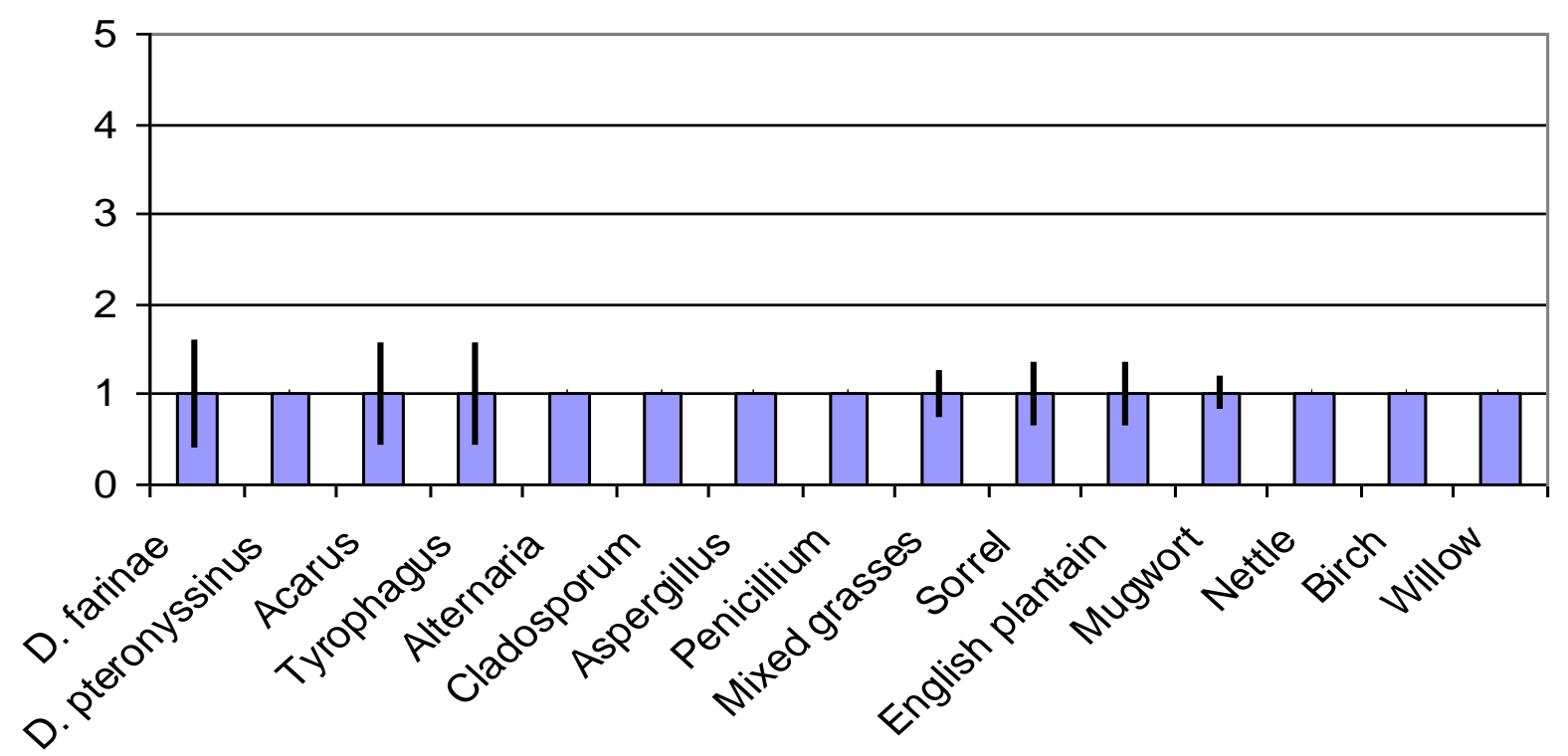

Figure 3

Intralaboratory variability of $L B$

Standard deviation (black lines) shown for the cut off value of $R G 1$

\subsection{Interlaboratory analysis}

Regarding interlaboratory variability, significant differences in OD units between LA and LC were detected for the mites Acarus siro, D. pteronyssinus and Lepidoglyphus destructor, the moulds Aspergillus fumigatus and Alternaria alternata, the trees willow and birch, the weed English plantain and cat epithelia (Table 2). There was a good correlation in 13 of 35 allergens (Table 2). Significant differences in RG between the three laboratories were found for 4 of 15 allergens: nettle $(p=0.0021)$, mixed grasses $(p=0.0104)$, Alternaria alternata ( $p=0.0159)$, and willow $(p=0.044)$ (Table 2). For analysis of correlation of RG, moulds had to be excluded since the majority of measurements showed RG 0 (data not shown). A good correlation between LA and LB was found for all allergens except D. pteronyssinus 
$(r=0.62)$. Correlation between LA and LC was good except for nettle $(r=0.79)$. LB and LC correlated well, with the exception of D. pteronyssinus $(r=0.7)$, nettle $(r=0.71)$ and mixed grasses $(r=0.76)$ (Table 2). Interlaboratory differences in rating a result as positive or negative were evaluated separately for the 20 allergens measured only by LA and LC and for the 15 allergens measured by all three laboratories. Results differed 4 times (1.34\%) in the 300 measurements carried out by LA and LC alone. Of the remaining 225 measurements from all three laboratories, discrepancies were found in 21 (9.33\%). LB differed twelve times from the other two, LC disagreed five times and LA four times. Overall disparity in 525 measurements was $4.76 \%(25 / 525)$. 


\begin{tabular}{|c|c|c|c|c|c|c|}
\hline $\begin{array}{l}\text { Laboratories } \\
\text { Allergens }\end{array}$ & $\begin{array}{l}\text { LA / LC } \\
\text { Variability } \\
\text { (OD } \\
\text { values) }\end{array}$ & $\begin{array}{l}\text { Coefficient } \\
\text { of } \\
\text { correlation } \\
\text { (OD } \\
\text { values) }\end{array}$ & $\begin{array}{l}\text { LA/LB/LC } \\
\text { Variability } \\
\text { (RG) }\end{array}$ & $\begin{array}{l}\text { LA / LB } \\
\text { Coefficient } \\
\text { of } \\
\text { correlation } \\
\text { (RG) }\end{array}$ & $\begin{array}{l}\text { LA / LC } \\
\text { Coefficient } \\
\text { of } \\
\text { correlation } \\
\text { (RG) }\end{array}$ & $\begin{array}{l}\text { LB / LC } \\
\text { Coefficient } \\
\text { of } \\
\text { correlation } \\
\text { (RG) }\end{array}$ \\
\hline Mites & & & & & & \\
\hline $\begin{array}{l}\text { Dermatophagoides } \\
\text { farina }\end{array}$ & 0.0883 & $0.987^{* *}$ & 0.118 & $0.8882 * *$ & $0.9823 * *$ & $0.8937 * *$ \\
\hline $\begin{array}{l}\text { Dermatophagoides } \\
\text { ptyeronysinus }\end{array}$ & $0.0189^{*}$ & 0.747 & 0.1385 & 0.6173 & $0.8779 * *$ & 0.7032 \\
\hline Acarus siro & $0.0034^{*}$ & $0.982^{\star *}$ & 0.7145 & $0.9067^{* *}$ & $0.8629 * *$ & $0.9186 * *$ \\
\hline $\begin{array}{l}\text { Tyrophagus } \\
\text { putrescentiae }\end{array}$ & 0.4285 & $0.921^{\star *}$ & 0.925 & $0.959 * *$ & $0.9332 * *$ & $0.9019 * *$ \\
\hline $\begin{array}{l}\text { Lepidoglyphus } \\
\text { destructor } \\
\text { Moulds }\end{array}$ & $0.0044^{*}$ & 0.764 & n.m. & n.m. & n.m. & n.m. \\
\hline Alternaria alternata & $0.0003^{*}$ & 0.429 & $0.0159^{*}$ & Excl. & Excl. & Excl. \\
\hline $\begin{array}{l}\text { Cladosporium } \\
\text { herbarum }\end{array}$ & 0.0564 & 0.095 & 0.3806 & Excl. & Excl. & Excl. \\
\hline $\begin{array}{l}\text { Aspergillus } \\
\text { fumigates }\end{array}$ & $0.0426^{*}$ & -0.151 & 1 & Excl. & Excl. & Excl. \\
\hline $\begin{array}{l}\text { Penicillium } \\
\text { Grasses }\end{array}$ & 0.0974 & 0.497 & 0.3297 & Excl. & Excl. & Excl. \\
\hline $\begin{array}{l}\text { Mixed grasses } \\
\text { (Gramineae } \\
\text { mixtum) }\end{array}$ & 0.1743 & $0.93^{* *}$ & $0.0104^{*}$ & $0.8675^{* *}$ & $0.9608 * *$ & 0.7564 \\
\hline $\begin{array}{l}\text { Bent grass } \\
\text { (Argostis alba) }\end{array}$ & 0.1312 & $0.942^{* *}$ & n.m. & n.m. & n.m. & n.m. \\
\hline $\begin{array}{l}\text { Bermuda grass } \\
\text { (Cynodon } \\
\text { dactylon) }\end{array}$ & 0.6392 & 0.713 & n.m. & n.m. & n.m. & n.m. \\
\hline $\begin{array}{l}\text { Johnson grass } \\
\text { (Sorghum } \\
\text { halepensis) } \\
\text { Weeds }\end{array}$ & 0.1226 & 0.754 & n.m. & n.m. & n.m. & n.m. \\
\hline $\begin{array}{l}\text { Sorrel (Rumex } \\
\text { crispus) }\end{array}$ & 0.7543 & $0.874^{\star *}$ & 0.0768 & $0.9317^{* *}$ & $0.8379 * *$ & $0.8588 * *$ \\
\hline $\begin{array}{l}\text { English plantain } \\
\text { (Plantago } \\
\text { lanceolata) }\end{array}$ & $0.0315^{\star}$ & 0.534 & 0.1349 & $0.8977^{* *}$ & $0.9985^{* *}$ & $0.8777 * *$ \\
\hline $\begin{array}{l}\text { Mugwort } \\
\text { (Artemisia } \\
\text { vulgaris) }\end{array}$ & 0.906 & $0.843^{\star *}$ & 0.167 & $0.8458^{* *}$ & $1^{* *}$ & $0.8458 * *$ \\
\hline $\begin{array}{l}\text { Lamb's quarters } \\
\text { (Chenopodium } \\
\text { album) }\end{array}$ & 0.3163 & $0.97^{* *}$ & n.m. & n.m. & n.m. & n.m. \\
\hline
\end{tabular}




\begin{tabular}{|c|c|c|c|c|c|c|}
\hline $\begin{array}{l}\text { Nettle (Urtica } \\
\text { dioica) }\end{array}$ & 0.3533 & $0.802^{\star *}$ & $0.0021^{*}$ & $0.8977^{* *}$ & 0.7915 & 0.7059 \\
\hline $\begin{array}{l}\text { Ragweed } \\
\text { (Ambrosia mixtum) }\end{array}$ & 0.1264 & 0.733 & n.m. & n.m. & n.m. & n.m. \\
\hline $\begin{array}{l}\text { Parietaria } \\
\text { officinalis }\end{array}$ & 0.1827 & $0.878^{\star *}$ & n.m. & n.m. & n.m. & n.m. \\
\hline $\begin{array}{l}\text { Salsola kali } \\
\text { Trees }\end{array}$ & 0.4841 & 0.785 & n.m. & $\begin{array}{l}\text { n.m. } \\
\text { n.m. }\end{array}$ & n.m. & $\begin{array}{l}\text { n.m. } \\
\text { n.m. }\end{array}$ \\
\hline Birch (Betula) & $0.0324^{*}$ & 0.593 & 0.2537 & $1^{\star *}$ & $0.9974 * *$ & $0.9974 * *$ \\
\hline Alder (Alnus) & 0.1536 & 0.518 & n.m. & n.m. & n.m. & n.m. \\
\hline Oak (Quercus) & 0.2329 & 0.738 & n.m. & n.m. & n.m. & n.m. \\
\hline $\begin{array}{l}\text { Cypress } \\
\text { (Cupressus) }\end{array}$ & 0.207 & $0.84^{\star *}$ & n.m. & n.m. & n.m. & n.m. \\
\hline $\begin{array}{l}\text { Hazel (Corylus } \\
\text { avellana) }\end{array}$ & 0.336 & 0.787 & n.m. & n.m. & n.m. & n.m. \\
\hline $\begin{array}{l}\text { Elm (Ulmus } \\
\text { campestris) }\end{array}$ & 0.5896 & 0.629 & n.m. & n.m. & n.m. & n.m. \\
\hline $\begin{array}{l}\text { Beech (Fagus } \\
\text { sylvatica) }\end{array}$ & 0.9005 & $0.865^{\star \star}$ & n.m. & n.m. & n.m. & n.m. \\
\hline Poplar (Populus) & 0.4836 & 0.387 & n.m. & n.m. & n.m. & n.m. \\
\hline $\begin{array}{l}\text { Maple (Acer } \\
\text { pseudoplantanus) }\end{array}$ & 0.3326 & 0.632 & n.m. & n.m. & n.m. & n.m. \\
\hline Willow (Salix) & $0.0042^{*}$ & 0.606 & 0.044 & $0.8329 * *$ & $0.9278 * *$ & $0.8977 * *$ \\
\hline $\begin{array}{l}\text { Olive (Olea } \\
\text { europaea) } \\
\text { Miscelanous }\end{array}$ & 0.1288 & $0.83^{* *}$ & n.m. & n.m. & n.m. & n.m. \\
\hline $\begin{array}{l}\text { Flea saliva } \\
\text { (Ctenocephalides } \\
\text { saliva) }\end{array}$ & 0.6655 & 0.412 & n.m. & n.m. & n.m. & n.m. \\
\hline $\begin{array}{l}\text { Cat dander (Felis } \\
\text { catus epithelium) }\end{array}$ & $0.0054^{*}$ & 0.123 & n.m. & n.m. & n.m. & n.m. \\
\hline $\begin{array}{l}\text { Cockroach } \\
\text { (Blatella } \\
\text { germanica) }\end{array}$ & 0.7068 & -0.245 & n.m. & n.m. & n.m. & n.m. \\
\hline
\end{tabular}

Table 2:

Interlaboratory variability and correlation

*: significant variability $(p<0,05)$

**: good correlation $(r>0,8, p<0,001)$

n.m.: Allergen not measured

Excl.: Allergen excluded: Molds were excluded form analysis of interlaboratory correlation in $R G$, since majority of measurements was $R G 0$. 


\section{Discussion}

This report describes the first systematic study of intra and interlaboratory variability among commercial laboratories offering the Allercept1 Fc-e receptor test. The results of the present study show that variability among these three laboratories of "Allercept Program Lab Partners" is not much higher than the variability within each single laboratory. This may be due to the fact that these laboratories are provided with the same defined allergen reagents and are trained in standardised performance of the test method. Although Heska developed the Allercept ${ }^{\circledR}$ Fc-e receptor test, we did not consider any laboratory superior to the others. In practice most veterinarians and laboratories will differentiate between positive and negative results to determine, which allergen is to be included in an allergen extract for therapeutic purposes. Intralaboratory variability regarding positive or negative interpretation of the test revealed that altogether only $3.14 \%$ of the measurements differed. In LA as well as in LC $3.24 \%$ disagreed, in LB there were $2.66 \%$ differing results. Interlaboratory results regarding a positive/negative test result for the 20 allergens measured only by LA/LC differed less often $(1.34 \%)$ than for the 15 measured by all three laboratories $(9.33 \%)$. Those disagreements occurred noticeably more often between LB and the other two laboratories. However, there is no indication which of the laboratories had false positive/false negative results. Overall interlaboratory disparity in 525 measurements can be considered low with $4.76 \%$. As there is no evidence that the level of allergen-specific IgE correlates with the severity of clinical disease, the decision to use individual allergens for ASIT is based on positive or negative test results and the clinicians' validation of their clinical relevance. As shown in Fig. 2 , the probability to get a false positive or false negative result is highest in the OD interval of 50-500. OD values of 647 from 2100 measurements by LA and LC lay within this critical range and all but 7 of the results differing either intra- or interlaboratory lay within it. In this range any test result should be interpreted carefully. LB considered this fact in its classification of RG by dividing this range into 3 grades. RG 0,1 , and 2 grade only small intervals of 100-150 OD units each (Table 1). Nevertheless, interpretation of the results and correlation with clinical history are more difficult without knowing the exact OD value. Comparing results within as well as between laboratories, allergens with a very high or very low OD value (or higher RG) less often show differing results in terms of positive versus negative than those closer to the cut-off value (i.e. 50-500 OD). Altogether, intralaboratory variability was comparable in LA and LC. As shown in Fig. 3, the probability distribution functions are nearly identical and dispersion factors for individual allergens are comparable 
between the laboratories (Fig. 1). Results of LB, provided in RG, are abstracted and therefore inexact. They cannot be directly compared to the OD results of the other two laboratories. This fact complicated comparison of the three laboratories. However, in order to provide a blinded study design, the laboratory was not aware of participating in this study. When we prospectively asked laboratory B to provide us with OD instead of RG on a routine basis, they refused this request. Strengths of this study include the large number of tests and the blinding prior to analysis by all laboratories. Even though one laboratory (Heska Ag, Fribourg, Switzerland) was aware of the study protocol, samples were sent in batches of multiple sera with different owner and dog names to avoid bias. In veterinary medicine, there are no standardised guidelines on how to interprete data on variance of serological allergy test methods. There is neither a laboratory accreditation nor a quality assurance program for serum allergen-specific IgE testing nor are recognised standard allergen extracts for calibration of assays available (DeBoer and Hillier, 2001). However, the International Task Force for Canine Atopic Dermatitis currently is working on a voluntary quality assurance program (RM, Personal Communication). In human medicine the Clinical Laboratory Improvement Amendments (CLIA) requires all licensed medical laboratories in the USA performing testing for allergenspecific IgE to take part in an external interlaboratory proficiency survey. However accepted coefficient of variation is only established for total $\mathrm{IgE}$ and not for allergenspecific IgE (Hamilton and Adkinson, 2003; King et al., 2007). The comparison of allergen-specific IgE measured by different assays shows major limitations, as allergen preparations vary in their immunogenicity and allergic potency between manufacturers and batches of allergen preparations. Influencing factors are the season in which the raw material is collected, cross contamination, different extraction processes during allergen-reagent production and stability of the extract during storage (Hamilton and Adkinson, 2003). Another important limitation for the validation of serum allergy tests is the lack of an objective standard (Williams et al., 2000). Intradermal allergy testing (IDT), although regarded as the "nearest gold standard available" in clinical practice (Patterson et al., 2005), has the same limitations in terms of allergen standardisation. Several reports have shown a poor correlation between results of IDT and serological test methods (Codner and Lessard, 1993; Bond et al., 1994; Haemmerling and De Weck, 1998; Wassom and Grieve, 1998; Park et al., 2000; Foster et al., 2003; Patterson et al., 2005). Therefore we did not compare our IDT to the serological results. One way of evaluating intralaboratory reproducibility could be the creation of an "ideal assay" using serial dilution (Williams et al., 2000). In a study evaluating allergen-specific IgE levels in human sera this serial dilution was 
used. Five test methods in six commercial laboratories were compared on different days. Four of five assays demonstrated a substandard overall performance and several times a poor precision and accuracy, especially for weeds and moulds (Williams et al., 2000). In a study by Patterson et al. (2005), using a commercial alkaline phosphatase ELISA for semi-quantitative detection of canine allergen-specific IgE, significant differences in duplicate serum samples that were stored under different conditions were reported. As serum IgE antibodies are quite stable (Johansson and Yman, 1988), the most likely explanation for these suboptimal results is an inter-day or inter-batch variance. The suboptimal results in two studies (Williams et al. 2000; Patterson et al., 2005) using monoclonal ELISA and RAST type assays are in contrast to our findings for the $\mathrm{Fc}$-e receptor test. In our study aliquots were shipped after the same storage time at $-18{ }^{\circ} \mathrm{C}$ for each aliquot and were analysed on the same day, probably in the same batch of measurements. Therefore in fact we evaluated the intra-assay variation. The inter-day or inter-batch variance, another important factor of reproducibility, is not evaluated by our study. Plant (1994) evaluated intralaboratory reproducibility on the same day in three different laboratories. He found a high reproducibility for one laboratory which had shown a significant difference in the aforementioned study by Patterson et al. (2005). This is in concordance with our findings. However, reproducibility of "same-day analyses" of two other laboratories was unsatisfactory with only $76 \%$ and $57 \%$ (Plant, 1994). To assess, if there is an "inter-day" or "inter-batch" variance in the same test method in the same laboratory, requires further studies involving multiple batches of assays on different days within the same laboratories. However, results of the present study show that even interlaboratory variability among these 3 laboratories using the same test method is acceptable. As long as there is a lack of an external and independant quality assurance for testing of serum allergen-specific IgE, independant peer-reviewed studies are needed to verify reliability of test results. Three laboratories using the Allercept $1 \mathrm{Fc}$-e receptor test demonstrated a moderate intra- and interlaboratory variability. This variability was most prominent and of clinical relevance with low OD values around the cut-off point. Although the variability of laboratories using the same test method was acceptable in the present study, an independent quality assurance programme is needed to confirm reliability of serological measurement of allergenspecific IgE in veterinary medicine.

\section{Acknowledgement}

This study was partially funded by a grant of the German Society of Veterinary Dermatology. 


\section{References}

Bond, R., Thorogood, S.C., Lloyd, D.H., 1994. Evaluation of two enzymelinked immunosorbent assays for the diagnosis of canine atopy. Vet. Rec. 135, 130-133.

Codner, E.C., Lessard, P., 1993. Comparison of intradermal allergy test and enzyme-linked immunosorbent assay in dogs with allergic skin disease. JAVMA 202, 739-743.

DeBoer, D.J., Hillier, A., 2001. The ACVD task force on canine atopic dermatitis (XVI): laboratory evaluation of dogs with atopic dermatitis with serum-based "allergy' tests. Vet. Immunol. Immunopathol. 81, 277-287.

Foster, A.P., Littlewood, J.D., Webb, P., Wood, J.L., Rogers, K., Shaw, S.E., 2003. Comparison of intradermal and serum testing for allergenspecific IgE using a Fce RIa-based assay in atopic dogs in the UK. Vet. Immunol. Immunopathol. 93, 51-60.

Griffin, C.E., Hillier, A., 2001. The ACVD task force on canine atopic dermatitis: allergenspecific immunotherapy. Vet. Immunol. Immunopathol.81, 363-383.

Haemmerling, R., De Weck, A.L., 1998. Comparison of two diagnostic tests for canine atopy using monoclonal anti-IgE antibodies. Vet. Derm. 9, 191-199.

Halliwell, R.E.W., 2006. Revised nomenclature for veterinary allergy. Vet. Immunol. Immunopathol. 114, 207-208.

Hamilton, R.G., Adkinson, N.F., 2003. Clinical laboratory assessment of IgE-dependent hypersensitivity. J. Allergy Clin. Immunol. 111, 687-701.

Hillier, A., Griffin, C.E., 2001. The ACVD task force on canine atopic dermatitis: incidence and prevalence. Vet. Immunol. Immunopathol. 81, 147-151.

James, L.K., Durham, S.R., 2008. Update on mechanisms of allergen injection immunotherapy. Clin. Exp. Allergy 38, 1074-1088. 
Johansson, S.G.O., Yman, L., 1988. In vitro assays for immunoglobulin E. Methodology, indications, and interpretation. Clin. Rev. Allergy 6, 93- 139.

Keppel, K.E., Campbell, K.L., Zuckermann, F.A., Greeley, E.A., Schaeffer, D.J., Husmann, R.J., 2008. Quantification of canine regulatory T-cell populations and serum interleukin-1 concentrations in healthy control dogs and canine atopic dermatitis patients receiving allergen-specific immunotherapy. Vet. Immunol. Immunopathol. 123, 337-344.

King, E.M., Vailes, L.D., Tsay, A., Satinover, S.M., Chapman, M.D., 2007. Simultaneous detection of total and allergen-specific IgE by using purified allergens in a fluorescent multiplex array. J. Allergy Clin. Immunol. 120, 1126-1131.

Park, S.J., Ohya, F., Yamashita, K., Nishifuji, K., Iwasaki, T., 2000. Comparison of response to immunotherapy by intradermal skin test and antigen-specific IgE in canine atopy. J. Vet. Med. Sci. 62, 983-988.

Patterson, P., Schaeffer, D.J., Campbell, K.L., 2005. Reproducibility of a commercial in vitro allergen-specific assay for immunoglobulin E in dogs. Vet. Rec. 157, 81-85.

Plant, J.D., 1994. The reproducibility of three in vitro canine allergy tests: a pilot study. In: Proceedings of the Members' Meeting of the American Academy of Veterinary Dermatology and American College of Veterinary Dermatology, Charleston, USA, pp. 16-18.

Prelaud, P., 1998. Diagnostic de la dermatite atopique canine: un diagnostic clinique. Prat. Med. Chir. Anim. Comp. 33, 331-336.

Reedy, L.M., Miller, W.H., Willemse, T., 2002. Atopic diseases. In: Reedy, L.M., Miller, W.H., Willemse, T. (Eds.), Allergic Skin Diseases of Dogs and Cats. W.B. Saunders, Philadelphia, pp. 42-56.

Scott, D.W., Paradis, M., 1990. A survey of canine and feline skin disorders seen in a university practice. Can. Vet. J. 31, 830-835. 
Scott, D.W., Miller, W.H., Griffin, C.E., 2001. Skin immune system and allergic skin diseases. In: Scott, D.W., Miller, W.H., Griffin, C.E. (Eds.), Small Animal Dermatology. 6th edition. W.B. Saunders, Philadelphia, pp. 543-666.

Stedman, K., Lee, K., Hunter, S., Revoire, B., McCall, C., Wassom, D., 2001. Measurement of canine IgE using the alpha chain of the human high affinity IgE receptor. Vet. Immunol. Immunopathol. 78, 349-355.

Wassom, D.L., Grieve, R.B., 1998. In vitro measurement of canine and feline IgE: a review of FceR1a-based assays for detection of allergen reactive IgE. Vet. Derm. 9, 173-178.

Willemse, T., 1986. Atopic skin disease: a review and a reconsideration of diagnostic criteria. J. Small Anim. Pract. 27, 771-778.

Williams, P.B., Barnes, J.H., Szeinbach, S.L., Sullivan, T.J., 2000. Analytic precision and accuracy of commercial immunoassays for specific IgE: establishing a standard. J. Allergy Clin. Immunol. 105, 1221-1230. 